\title{
Efficacy of Auditory Verbal Therapy on Listening and Linguistic Skills of a Child with Bimodal Hearing
}

https://doi.org/10.47210/bjohns.2020.v28i3.293

Joyanta Chandra Mandal, ${ }^{1}$ Indranil Chatterjee, ${ }^{1}$ Suman Kumar, ${ }^{1}$ Shilpi Chakraborty ${ }^{l}$

Introduction

\section{ABSTRACT}

This study aimed to document the effect of Auditory Verbal Therapy (AVT) with proper assessment and management in early intervention of a child with bimodal hearing. Bimodal Hearing is the use of a cochlear implant in one ear and a hearing aid in the opposite ear. Auditory Verbal Therapy is a highly specialist early intervention programme which equips parents with the skills to maximise their deaf child's speech and language development.

Case Report

A male child aged 5 years 1 month had bilateral severe to profound hearing loss and speech-language problem. He was using cochlear implant in the right ear and BTE hearing aid in left ear (Bimodal hearing). Speech and language assessment revealed delayed semantic, syntax and pragmatic skills. Assessment of language development test showed poor receptive and expressive language score. The functional auditory performance indicator score indicated poor auditory function. Auditory verbal therapy hierarchy plan was used for treatment. Post 15 sessions after applying AVT the child's listening and linguistic skills showed a great improvement.

Discussion

The scales used to measure the efficacy of AVT are found to be useful for the assessment and goal setting for intervention. Thus, appropriate quantification of various aspects of communication skills may describe its potential impact in this case under ADIP scheme.

$\underline{\text { Keywords }}$

Hearing Loss; Cochlear Implantation; Bimodal Hearing; Auditory Verbal Therapy

$C$ ochlear Implant is surgically implanted device coupled to external components that provide useful hearing and improved communication to adults and youngsters with severe to profound hearing losses. ${ }^{1}$ In a bimodal fitting, one ear is stimulated acoustically with a hearing aid and the other is stimulated electrically with a cochlear implant. Appropriate medical and audiological management to ensure that amplification or a cochlear implant leave maximum access to speech. Auditory-Verbal Therapy (AVT) facilitates optimal acquisition of speech through listening by newborns, infants, toddlers, and young children who are deaf or hard of hearing. It promotes early diagnosis, one-on-one therapy, and state-of-the-art audiological management and technology. ${ }^{2}$ Auditory-Verbal Therapy is specialized type of therapy designed to teach a child to use the hearing provided by a hearing aid or a cochlear implant for understanding speech and learning to speak. The child is taught to develop hearing as a lively sense in order that listening becomes automatic and therefore the child seeks out sounds in life. Hearing and active listening becomes an integral a part of communication, recreation, socialization, education, and work. Under the ADIP scheme cochlear implant was done since there was little benefit from the BTE hearing aid. The parents

1 - Speech and language Diagnotic Department, Ali Yavar Jung National Institute of Speech \& Hearing Disabilities, RC, Kolkata

Corresponding author:

Dr Joyanta Chandra Mandal

email: joyantachmandal@gmail.com 
Table I: Audiological test reports.

\begin{tabular}{|c|c|c|c|c|}
\hline & TESTS & RIGHT EAR & LEFT EAR & IMPRESSION \\
\hline \multirow{6}{*}{ Pre-Implant } & PTA & 111.6 dBHL & $115 \mathrm{dBHL}$ & \multirow{4}{*}{$\begin{array}{l}\text { Bilateral profound } \\
\text { sensorineural } \\
\text { hearing loss. }\end{array}$} \\
\hline & SAT & 105dBHL (NR) & 105dBHL (NR) & \\
\hline & Immittance Test & 'A'-type & 'A'-type & \\
\hline & Acoustic Reflexes & Absent & Absent & \\
\hline & ASSR & $95 \mathrm{dBHL}$ & $98 \mathrm{dBHL}$ & $\begin{array}{l}\text { Bilateral profound } \\
\text { hearing loss. }\end{array}$ \\
\hline & ABR & 95dBnHL(NR) & 95dBnHL(NR) & $\begin{array}{l}\text { Bilateral severe to } \\
\text { profound hearing } \\
\text { loss. }\end{array}$ \\
\hline \multirow{3}{*}{ Post-Implant } & PTA & $120 \mathrm{dBHL}(\mathrm{NR})$ & $113.3 \mathrm{dBHL}$ & \multirow{3}{*}{$\begin{array}{c}\text { Bilateral profounc } \\
\text { sensorineural } \\
\text { hearing loss. }\end{array}$} \\
\hline & Immittance Test & 'A'-type & 'A'-type & \\
\hline & Acoustic Reflexes & Absent & Absents & \\
\hline
\end{tabular}

were concerned about the child's speech- language and listening skills as they were now entering into a different domain of therapeutics. This study aimed to document the effect of AVT with proper assessment and management in a child with bimodal hearing (cochlear implant with hearing aid).

\section{Case Report}

A male child aged 5 years 1 month with cochlear implant (Cochlear-CI24RE-CP802 under ADIP scheme) in the right ear and BTE hearing aid (Siemens Intuis DIR) in left ear was brought to the speech and language diagnostic department with the complaint of speechlanguage and hearing problem. He was from native Bengali speaking family and using few words along with gestures for his needs and came for rehabilitation purpose. His hearing age was 2 years with hearing aids. No history of developmental delay or any other medical conditions.

All audiological evaluation reports are shown in the Table I and aided free field responses are shown in Table II.

Speech and language assessment revealed semantic age-12-18months, syntax age-yet to enter Browns stage and pragmatic age-18-24 months. Assessment of language development (ALD) test showed receptive language score-8 (6-11months) and expressive language score-11 (12-17months). The functional auditory performance indicator (FAPI) score are tabulated in Table III. Overall parental satisfaction from implantation rating was 07 (considerable).

AVT Hierarchy Plan was used for treatment (Fig. 1$){ }^{3}$ Management included the main goal to facilitate age appropriate speech and language skills within the child's limit of participation. To accomplish that long term goal, three short term goals were taken, which included the target to improve auditory skills (Auditory awareness, Attention, Localization, Discrimination, Auditory feedback, Auditory memory and Auditory closure); second to facilitate the improvement of speech production and lastly to facilitate improvement of language skills. Therapy session was for 45 minutes, twice a week.

To achieve first goal means to improve listening and speech perception skills, the clinician was used different noise makers (drum, jhankara, whistle), rings/blocks, flash cards of 6 ling sounds (/ah/, /oo/, /ee/, /m/, /s/, / 
Table II: Free field aided responses

\begin{tabular}{|c|c|c|c|c|}
\hline & $500 \mathrm{HZ}$ & $1 \mathrm{KHZ}$ & $2 \mathrm{KHZ}$ & $4 \mathrm{KHZ}$ \\
\hline Unaided & $85 \mathrm{dBHL}(\mathrm{NR})$ & $90 \mathrm{dBHL}(\mathrm{NR})$ & $95 \mathrm{dBHL}(\mathrm{NR})$ & $95 \mathrm{dBHL}(\mathrm{NR})$ \\
\hline Only CI & $30 \mathrm{dBHL}$ & $40 \mathrm{dBHL}$ & $40 \mathrm{dBHL}$ & $45 \mathrm{dBHL}$ \\
\hline CI with Hearing aid & $25 \mathrm{dBHL}$ & $30 \mathrm{dBHL}$ & $25 \mathrm{dBHL}$ & $30 \mathrm{dBHL}$ \\
\hline
\end{tabular}

sh/- showed in Fig.2), daily objects and activity cards.

The clinician showed pictures of Six ling sounds(/a/, $/ \mathrm{u} /, / \mathrm{i} /, / \mathrm{m} /, / \mathrm{s} /, / \mathrm{s} /$ ) and produced each sound again and again till the child indicate them consistently by pointing to their pictures. Also to discriminate intensity/ pitch (Loud vs. Soft; High vs. Low), consonant and vowel difference in 1, 2, and 3 syllable words (/a:m/, /kola/, /a:narosh/) and discrimination between increasingly similar word also between consonant same but different vowel (/pet/,/pith/, /pa/; /bot/, /bæt, /bas/; /kæt/, /kot/, /kar/) and consonant that only differ by manner: (/bæt/, /mæt/). To improve auditory memory and auditory closure, clinician used identification of key word in context with and without suprasegmentals tasks like: two key words in context of one sentence, three key words in context of one sentence, 4+ words in one sentence (e.g. show me book, watch, plate and tree, Increase word play association through listening, answer simple questions (where, what, who) understand increasingly complex sentences.
Second goal was to facilitate improvement of speech production that was trained by making the child imitate single words which were spontaneously produced using with phonological cues and after sometime without cues. When the child spontaneously produced single words without using phonological processes the clinician moved towards the imitation of 10 different phases using 2-3 different words. Goal was to make the child spontaneously produce 10 different phrases with $80 \%$ intelligibility.

Thirdly the target was set to improve language skills which constituted the imitation of single words spontaneously with the help of common daily used objects $->$ initiation of two word phrases $->$ spontaneous production of 2-3 word sentences which was done by the clinician $->$ production and use of single words as well as 2 word utterances. Also the child was encouraged to use them in real life situations.

After 15 sessions of AVT the child listening and linguistic skills showed a great improvement. FAPI score

Table III: FAPI score

\begin{tabular}{|c|c|}
\hline CATEGORY & SCORE \& INTERPRETATION \\
\hline Sound awareness & $77.77 \%$ \\
\hline Sound meaningful & $59.52 \%$ \\
\hline Auditory feedback & $0 \%$ \\
\hline Localizing sound source & $0 \%$ \\
\hline Auditory discrimination & $0 \%$ \\
\hline Short term auditory memory & $0 \%$ \\
\hline Linguistic auditory & $0 \%$ \\
\hline
\end{tabular}




\begin{tabular}{|c|c|c|c|c|c|c|c|c|c|c|c|c|c|c|c|c|c|}
\hline \multicolumn{18}{|c|}{ PLANNING AUDITORY-VERBALTHERAPY FOR CHILDREN } \\
\hline \multicolumn{18}{|c|}{$\begin{array}{l}\text { Auditory Potential }+ \text { Cognitive-Linguistic Processes }+ \text { Motor Processes } \rightarrow \text { Auditory-Verbal Communication } \\
\begin{array}{lll}\text { (e.g., auditory access and processing) } & \text { (e.g, ideas, intent and language) } & \text { (e.g., planning and execution) }\end{array}\end{array}$} \\
\hline \multicolumn{18}{|c|}{$\begin{array}{l}\text { Variables to Consider } \\
\begin{array}{l}\text { etiology of hearing loss, age of diagnosis, degree of hearing loss, effectiveness of hearing technology, effectiveness of audiological management, hearing potential, general } \\
\text { health, leaming style, intelligence, emotional health, participation and involvement of the family, expertise and skills of the therapist }\end{array}\end{array}$} \\
\hline \multicolumn{18}{|c|}{ Hierarchies* } \\
\hline $\begin{array}{l}\text { Expressive } \\
\text { Language } \\
\end{array}$ & \begin{tabular}{|c|} 
Listening \\
Skills
\end{tabular} & \multicolumn{4}{|c|}{ Awareness of Sounds } & \multicolumn{8}{|c|}{ Auditory Memory } & \begin{tabular}{|l|} 
Auditory \\
Closure
\end{tabular} & \multicolumn{3}{|c|}{ Figure Ground } \\
\hline $\begin{array}{l}\text { - Crying } \\
\text { - Cooing } \\
\text { - Smilling } \\
\text { - Laughing } \\
\text { - Vocallizing } \\
\text { - Eabbling } \\
\text { - Imitating } \\
\text { - Elowing and } \\
\text { whispering } \\
\text { - Jargon } \\
\text { - First words } \\
\text { - Word } \\
\text { combinations } \\
\text { - Sentences } \\
\text { - Conversation } \\
\text { - Near } \\
\text { age-appropriate } \\
\text { grammar } \\
\text { - Age-appropriate } \\
\text { grammar }\end{array}$ & \begin{tabular}{|l|} 
- Auditiony \\
awareness \\
- Attention \\
- Localization \\
- Discrimination \\
- Auditory \\
fectlack \\
- Monitoring of \\
voices \\
- Auditory \\
memory \\
- Sequencing \\
- Comprehension
\end{tabular} & $\mid \begin{array}{c}6 \text { inches } \\
\vdots \\
3-6 \text { feet } \\
\vdots \\
12+\text { feet } \\
\downarrow \\
\text { Outside } \\
\text { doot } \\
\downarrow \\
\text { Outside } \\
\text { building }\end{array}$ & $\begin{array}{c}\text { Slow } \\
\downarrow \\
\text { Regular } \\
\downarrow \\
\text { Rapid }\end{array}$ & $\begin{array}{c}\text { Loud } \\
\downarrow \\
\text { Regular } \\
\downarrow \\
\text { Soft } \\
\downarrow \\
\text { Whisper }\end{array}$ & $\begin{array}{c}\text { Low } \\
\downarrow \\
\text { Mid } \\
\downarrow \\
\text { High }\end{array}$ & $\begin{array}{c}\text { Supre. } \\
\text { segmetal } \\
\text { leatures } \\
\downarrow \\
\text { Leaming } \\
\text { to Listen } \\
\text { sounds } \\
\downarrow \\
\text { Word } \\
\downarrow \\
\text { Phrase } \\
\downarrow \\
\text { Sentence }\end{array}$ & 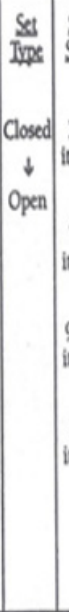 & 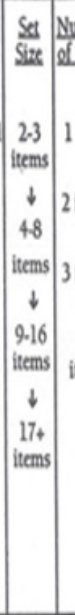 & $\begin{array}{c}\text { Number } \\
\text { d.liems } \\
1 \text { item } \\
\downarrow \\
2 \text { items } \\
\downarrow \\
3 \text { items } \\
\downarrow \\
4 \\
\text { items } \\
\end{array}$ & $\begin{array}{c}\text { Tarret } \\
\text { pesition } \\
\text { Isolated } \\
\text { word } \\
\downarrow \\
\text { End of } \\
\text { phrase } \\
\downarrow \\
\text { Middle of } \\
\text { phrase } \\
\downarrow \\
\text { Beginning } \\
\text { of parse }\end{array}$ & $\begin{array}{c}\text { sequence } \\
\text { Ou of } \\
\text { order } \\
\downarrow \\
\text { In order } \\
\end{array}$ & $\begin{array}{c}\text { Critical } \\
\text { Elements } \\
\\
1 \\
\text { clement } \\
\downarrow \\
2 \\
\text { elements } \\
\downarrow \\
3 \\
\text { dements } \\
\downarrow \\
4+ \\
\text { elements }\end{array}$ & $\begin{array}{c}1 \text { step } \\
\downarrow \\
2 \text { related } \\
\text { steps } \\
\vdots \\
2 \\
\text { unrelated } \\
\text { steps } \\
\downarrow \\
3 \text { steps } \\
\downarrow \\
4+\text { steps }\end{array}$ & 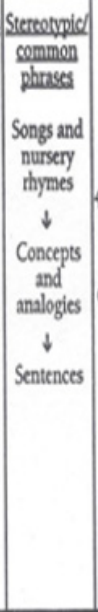 & $\begin{array}{c}\text { Noiss } \\
\text { Inss } \\
\text { Fan } \\
\downarrow \\
\text { 4-speaker } \\
\text { babble } \\
\downarrow \\
\text { Caleteria }\end{array}$ & $\begin{array}{c}\text { Disstincs } \\
\\
\text { Next to } \\
\text { sound } \\
\text { source } \\
\downarrow \\
5.6 \text { feet } \\
\text { from } \\
\text { source } \\
\downarrow \\
\text { accoss the } \\
\text { room }\end{array}$ & $\begin{array}{c}\text { Sutced } \\
\text { Noliss } \\
\\
\text { Continuous } \\
\downarrow \\
\text { Intemittent } \\
\text { with a } \\
\text { pattem } \\
\downarrow \\
\text { Continuous } \\
\text { with no } \\
\text { pattem }\end{array}$ \\
\hline
\end{tabular}

Fig.1. AVT Hierarchy Plan by Estabrooks (Image copied from “Auditory Verbal Practice")

showed sound awareness, sound meaningful, localizing sound source $100 \%$ (acquired), auditory feedback and auditory discrimination $91.66 \%$ and $95.5 \%$ (acquired) respectively, short term auditory memory $88.88 \%$ (acquired) and linguistic auditory was 15\% (emerging).

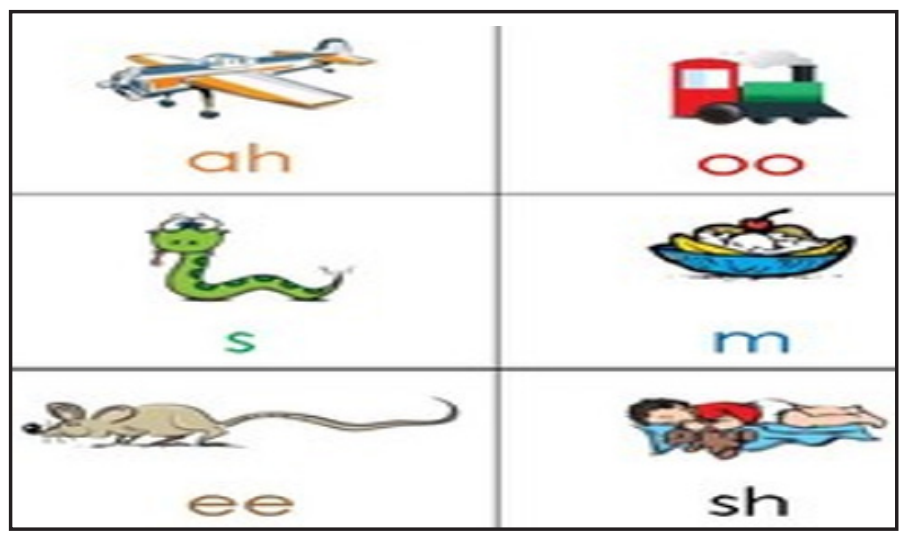

Fig. 2. Six Ling Sounds cards (Image copied from "www. teacherspayteachers.com" $)^{5}$
Assessment of language development (ALD)-Receptive language assessment-Score 13 (18-23 months) \{criteria met $\}$ and Expressive language assessment-Score 19 (2429 months) \{criteria met\}, Speech production showedBrown's stages for MLU assessment-Brown stage 1 (emerging) and Speech intelligibility rating scale-2 (can understand with little effort, occasionally need to ask for repetition), and Overall parental satisfaction from implantation-rating- 09 (tremendous). The child is now attending regular school and studies in upper kindergarten.

\section{Discussion}

AVT includes education, advocacy, guidance and family support as it states a major role of the parents. The assessment procedure was based on assessing the four domains that is listening and speech perception skills, language skills, speech production, as well as overall 
parental satisfaction from the implant. Management also included periodical mapping of the cochlear implant based on the child's responses. The primary goal of AVT is to guide parents in helping their children develop intelligible spoken language through listening and to coach parents in advocating their children's inclusion in mainstream schools.

Ongoing assessment of the child's development; auditory verbal therapy is diagnostic in nature and supports ongoing analysis of the child's progress. Integration into regular education the maximum amount as possible to permit for typical speech, language, and auditory models, as well as typical curriculum that supports age-appropriate academic and social learning. Integrating audition into the personality of the kid in order that listening is viewed as meaningful and first for learning and functioning within the mainstream of society. Parents and caregivers are viewed because the primary models for speech development, and remain as active participants throughout the child's intervention and education. Study also suggested that AVT can have a positive impact on developing speech and language skills in children with HI. ${ }^{6}$ It focuses on certain factors like- speech detection, auditory learning instead of visual learning, effective language learning, reading skills development, team approach to therapy that allows for a more complete education environment, stresses listening rather than watching and finally parents do not need to learn sign language. ${ }^{?}$

Improvements in cochlear implant technology and outcomes have resulted in expanded candidacy criteria. As a result, more implant recipients present with significant residual hearing and bimodal stimulation should be considered in order to provide access to bilateral, binaural \& complementary acoustic cues. The scales used to measure the efficacy of AVT are found to be useful for the assessment and goal setting for intervention. Thus, appropriate quantification of various aspects of communication skills may describe its potential impact in this case under ADIP scheme. Due to the inherent variability in the cochlear implant population, the approach that provides the most benefit will vary from patient to patient. Outcomes assessment is important in individualizing the AVT approach.

\section{References}

1. Katz, Jack, Larry Medwetsky, Robert Burkard, and Linda Hood. "Chapter 38, Hearing Aid Fitting for Adults: Selection, Fitting, Verification, and Validation." Handbook of Clinical Audiology (2009): 858

2. Houston T. "Auditory-verbal therapy: Supporting listening and spoken language in young children with hearing loss \& their families." ASHA Sphere, Rockville, MD: American SpeechLanguage-Hearing Association (ASHA) (2012)

3. Estabrooks W, MacIver-Lux K, Rhoades EA, eds. AuditoryVerbal Therapy: For Young Children with Hearing Loss and Their Families, and the Practitioners Who Guide Them. Plural Publishing, 2016

4. Estabrooks W. Auditory Verbal Practice. The Listener, Summer, 2000, 6-29

5. Krause E. "Activities Fun Stuff." Retrieved from Activities Fun Stuff: https://www. teacherspayteachers. com/Product/RoadTrip-Scavenger-Hunt-3756381 (2019)

6. Ramesh K, Danser ML. Efficacy of auditory-verbal therapy in children with hearing impairment: A systematic review from 1993 to 2015. International journal of pediatric otorhinolaryngology 2016; 86:124-34

7. Stith JL, Drasgow E. Including Children with Cochlear Implants in General Education Elementary Classrooms. Teaching exceptional children plus 2, no. 1 (2005): n1. 